Orbis Tertius, vol. XXVI, nº 34, e209, noviembre 2021 - abril 2022. ISSN 1851-7811

Universidad Nacional de La Plata

Facultad de Humanidades y Ciencias de la Educación

Centro de Estudios de Teoría y Crítica Literaria

\title{
"El esfuerzo delirante de la poesía": el vitalismo poético de el lagrimal trifurca (1968-1976)
}

\author{
"The delirious efford of poetry": the poetic vitalism of el lagrimal trifurca \\ (1968-1976)
}

(iD) Marina Maggi

marinamaggi1988@gmail.com

Universidad Nacional de Rosario, Argentina

CONICET, Argentina

Recepción: 11 Marzo 2021

Aprobación: 20 Julio 2021

Publicación: 01 Noviembre 2021

Cita sugerida: Maggi, M. (2021). "El esfuerzo delirante de la poesía": el vitalismo poético de el lagrimal trifurca (1968-1976). Orbis Tertius, 26(34), e209. https://

doi.org/10.24215/18517811e209

\begin{abstract}
Resumen: El presente artículo se propone el análisis del proyecto poético que atraviesa la revista rosarina el lagrimal trifurca (1968-1976), a partir de la hipótesis de lectura que afirma que la publicación despliega en ciertos textos claves destacados por sus editores una perspectiva específica acerca de la actividad poética y su vínculo con el presente. La construcción de un abordaje literario en las páginas de la publicación apela a una vertiente vitalista, estrechamente ligada a la formulación de un compromiso poético diferenciado del imperativo sartreano respecto a la responsabilidad histórica de los escritores.
\end{abstract}

Palabras clave: El lagrimal trifurca, Publicación periódica, Proyecto poético, Compromiso, Vitalismo.

\begin{abstract}
This article analyses the poetic project of the magazine el lagrimal trifurca (1968-1976), based on the hypothesis that affirms that the publication displays in certain key texts highlighted by its editors a specific perspective about the poetic activity and its relation with the present. The construction of a literary approach in the pages of the publication appeals to a vitalist aspect, closely linked to the formulation of a poetic commitment differentiated from the Sartrean imperative regarding the historical responsibility of the writers.
\end{abstract}

Keywords: El lagrimal trifurca, Magazine, Poetic project, Commitment, Vitalism.

\section{INTRODUCCIÓN}

En 1968 se publica en Rosario el primer número de el lagrimal trifurca, bajo la dirección de Francisco y Elvio Gandolfo. Su "núcleo de hierro" (Gandolfo, 2015, p. 18) incluye también a Eduardo D'Anna y a Hugo Diz. Entre sus colaboradores se encuentran Samuel Wolpin, Sergio Kern (hijo de Francisco Gandolfo, quien utiliza para su pseudónimo artístico el apellido materno), Juan Carlos Martini y Luis Sienra. La revista publica catorce números distribuidos en dos lapsos que van de 1968 a 1970 (№ 1 al 8) y de 1972 a 1976 (No 9 al 14, bajo la exclusiva dirección de Elvio Gandolfo).

Las lecturas críticas dedicadas a el lagrimal ${ }^{1}$ perciben su legado como eminentemente poético. Esto no se debe a la exclusividad o la jerarquización de la poesía por sobre la prosa - hecho que puede constatarse fácilmente al revisar sus números-, sino en el reconocimiento de una poética compartida. Freidemberg (1986) la define como "un modo de encarar la producción textual" que no "se encauza" (p. 22) en los 
contenidos que pone en circulación, sino en los libros de sus autores. Es necesario volver sobre esta afirmación, que desliga la actitud poética común de la sintaxis de la publicación y presupone una discontinuidad entre esta última y las obras de sus editores. El hecho de que la poesía publicada en sus páginas sea "heterogénea" (Battilana, 2008, p. 17) y por lo tanto irreductible a una única "línea" estética (Freidemberg, 1986, p. 22), no significa que la revista no ponga en escena la formación de un abordaje literario.

El objeto de este trabajo es delimitar y caracterizar el proyecto poético que atraviesa el lagrimal. Este involucra la construcción de un punto de vista sobre la actividad poética y su vínculo con el presente, que es posible rastrear en ciertos textos clave puestos de relieve por los editores. En ellos emerge una concepción vitalista, ligada a la formulación de un compromiso poético.

El corpus sometido análisis incluye la "Nota de la dirección" sin firmar que abre el No 1, el reportaje al poeta martiniqués Aimé Césaire citado en la apertura del No 7 a modo de mensaje editorial y reproducido integralmente en el No 8 y el ensayo "Cinco tesis sobre poesía" de Raúl Gustavo Aguirre, publicado No 14. Si bien los últimos dos no son escritos por los miembros, constituyen instancias en las que la discursividad de la revista adquiere un sesgo crítico respecto al propio proyecto.

\section{LA POESÍA COMO “MOVILIZACIÓN” Y “RECREACIÓN” DE LA REALIDAD}

El primer número de el lagrimal presenta una breve "Nota de la dirección" sin firmar, que describe el propósito de la revista:

"El lagrimal trifurca" es una publicación trimestral en la que trataremos de mostrar el esfuerzo solidario y vital que vienen realizando los poetas, escritores y artistas de nuestro continente y del mundo por la literatura al servicio de la vida, la palabra como conocimiento totalizador y elemento renovador y dinámico (p. 38). ${ }^{2}$

La actividad literaria tendría asignadas dos funciones complementarias: conocer y renovar la realidad. Si bien el ideal de un "conocimiento totalizador" se aproxima en cierto punto al planteo sartreano de un "hombre total" capaz de elegir "el sentido de su condición y la de sus camaradas" (Sartre, 1948, p. 21), los editores reconocen a "la palabra" un estatuto que excede la concepción instrumentalista que atraviesa ¿Qué es la literatura? (1948).

Según la teoría del compromiso que postula Sartre, la obra literaria sería el espacio en que un sujeto autoconsciente pone en acto la búsqueda de la verdad, cuyo discernimiento y exposición se desenvuelve a través de un lenguaje claro, en el que "la palabra pasa a través de nuestra mirada como el sol a través del cristal” (1948, p. 51). Desde esta perspectiva, la significación constituiría la propiedad determinante de la escritura y la búsqueda expresiva implicaría un trato exclusivo con los signos como unidades de sentido. A partir de esta premisa, la prosa y la poesía se opondrían en tanto formas de escritura que involucran distintas actitudes frente al lenguaje. Sartre aclara que su análisis se refiere a la poesía contemporánea, cuyo estatuto conflictivo se remonta a la modernidad. El advenimiento de la sociedad burguesa y el consecuente fracaso del proyecto humanista habrían puesto en entredicho la potencia comunicativa del lenguaje: "la crisis de lenguaje que se produjo a comienzos del siglo fue una crisis poética" (1948, p. 48). La poesía habría asumido este fracaso a partir de una apuesta por "la sugestión de lo incomunicable" (1948, p. 63) y no podría, por ello, posicionarse ante la historia. Los poetas serían "hombres que se niegan a utilizar el lenguaje" (1948, p. 45, cursivas del autor), en razón de una cierta "actitud del espíritu" (1948, p. 51) que considera las palabras "como cosas y no como signos" (1948, p. 46). Su "materia” los colocaría "del lado de la pintura, la escultura y la música”, cuyos colores, formas y notas no remiten "a nada que les sea exterior" (1948, p. 45). Para ilustrar su reflexión, Sartre recurre a la figura del hablante. Mientras que éste se encuentra "situado" en el discurso, rodeado por "un cuerpo verbal del que apenas tiene conciencia y que extiende su acción por el mundo" (1948, p. 46), el poeta estaría "fuera del lenguaje", "como si no perteneciera a la condición humana y, viniendo hacia los hombres, encontrara en primer lugar la palabra como una barrera” (1948, p. 47). La poesía excluiría el movimiento de 
la nominación, debido a que el sentido que aloja su "cuerpo verbal" sería indisociable de la densidad asociativa de la "frase-objeto" (1948, p. 48). Esta substancia escritural no señala hacia ningún exterior, sino que "atrapa" las significaciones en imágenes totales, cerradas sobre sí, de las que emana "una tonalidad, un gusto” (1948, p. 49). Consecuentemente, sería "una tontería" reclamar "un compromiso poético" (1948, p. 50). La autonomía absoluta del género impediría enlazar el "imperativo estético" al "imperativo moral” (1948, p. 82), tal como sucede en la prosa. Si el escritor "proporciona a la sociedad una conciencia inquieta" (1948, p. 98), el poeta se limitaría a la función compensatoria de testimoniar, en el "fracaso de su propia vida" — que se espeja en una escritura de "oscuras resonancias" (1948, p. 64), concebida como un acto autosuficiente-, la "derrota humana general” (1948, p. 63). Tal como desarrollaremos, el lagrimal se distancia de estos presupuestos a partir de la afirmación de la potencia transformadora de la actividad poética.

Para los editores, sería el lenguaje (y no la voluntad del autor) el que aloja una forma de conocimiento y un poder de renovación. Por otra parte, la praxis literaria no se desenvolvería como el proyecto de un "un hombre que se sirve de las palabras" (Sartre, 1948, p. 51) para expresar un sentido y asumir su responsabilidad intelectual, sino como una labor solidaria que aboga por una literatura "al servicio de la vida”. El agenciamiento colectivo de un cambio existencial y el reconocimiento de fuerzas intrínsecas al "elemento" verbal difuminan en este planteo los alcances del compromiso político de cuño sartreano. En este marco, el lagrimal rehúye la toma de posición orgánica respecto a la causa revolucionaria, fenómeno que atraviesa y magnetiza el campo intelectual del período. Elvio Gandolfo (2015) hace alusión a esta postura: “no necesitábamos plantearnos que estábamos 'en otra': nos salía solo. Por ejemplo, Sartre no nos interesaba casi nada (...). En cambio, nos pasó por arriba completa la ola de la Revolución Cubana” (2015, p. 20). La fascinación por esta última, plasmada a partir de la metáfora de "la ola", es deslindada del llamado de Sartre a la responsabilidad histórica de los escritores. La moral literaria que delinea semejante exigencia emerge como un horizonte poco llamativo, cuyo cariz programático sería desbordado por la magnitud y la novedad a ultranza que acarrea el hecho revolucionario. Más próximo a la temporalidad de la inminencia (Manzano, 2017, p. 117) —en la que el presente se piensa a sí mismo a partir de los sueños del porvenir- que, del pasado reciente, este emerge como el punto de anclaje y proyección de un giro de la historia a gran escala. Despunta en este testimonio una disposición sensible frente al hecho social, que se resiste a ser asimilada al carácter asertivo que hace a toda declaración de principios. Esto no implica la negación del imaginario político de la revolución como horizonte interpelativo, sino su trasposición al "polo" de la obra (Gilman, 2012, p. 144) bajo la forma de un interés modernizador dirigido hacia las novedades que contribuyen a expandir y modificar nuestra conciencia de la realidad. ${ }^{3}$ La intención de "mostrar" las producciones que se realizan en el ámbito internacional no conlleva, en este contexto, la postulación de un programa estético-político que guíe la elección de los textos y autores publicados. La revista se guía más bien por una convicción profunda acerca del trabajo con el lenguaje, que portaría un saber y un brío innovador capaces de movilizar la conciencia colectiva.

el lagrimal se distancia del existencialismo sartreano a partir de la impronta cosmopolita y neohumanista que deja en sus páginas el contacto con agentes de la cultura underground, espacio de sociabilidad alternativo respecto a las redes intelectuales más representativas del periodo (Manzano). Elvio Gandolfo conoce en 1967 a Miguel Grinberg, editor de Eco contemporáneo (1961-1969). El encuentro tiene lugar en Buenos Aires a través de Wolpin, encargado de su distribución en Rosario.

La revista porteña Eco contemporáneo publica trece números entre 1961 y 1969. Sus colaboradores frecuentes son Antonio Dal Masetto y Juan Carlos Kreimer (Gatto, 2010). Según Ezequiel Gatto (2012), este proyecto debe ser pensado como una "presencia articuladora" (p. 177) en el ámbito nacional y continental, ya que su objetivo es funcionar como nexo de comunicación entre diversos emprendimientos colectivos, destinados a forjar modos de vida alternativos al orden instituido. En su primera etapa (1961-1965), la publicación asigna un lugar central a la poesía latinoamericana y estadounidense (Gatto, 2010). Junto con el corno emplumado (1962-1969), dirigida por Margaret Randall y Sergio Mondragón, Eco contemporáneo 
organiza el Primer Encuentro Americano de Poetas (PEAP), bautizado por Grinberg como "Primer Encuentro de la Nueva Solidaridad" (Silva Ibargüen, 2017, p. 164). Este evento autogestivo (sin apoyo institucional alguno) se realiza en México y convoca a un amplio número de poetas y jóvenes escritores. A partir de estos intercambios, se materializa el Movimiento Nueva Solidaridad, cuya declaración final (AA.VV.) se opone a la deshumanización de las sociedades tecnocráticas de la segunda posguerra. Esta posición se distancia de aquella asumida por las nuevas izquierdas latinoamericanas y se sustenta sobre "una perspectiva lúdica y un rechazo de formas organizativas que pudieran burocratizarse" (Manzano, p. 117). Dentro del circuito poético, los principales representantes de esta tendencia son los beatniks, cuyo discurso combina "existencialismo, mística y una crítica más o menos abierta al orden social” (Gatto, 2010, s/p).

Elvio Gandolfo se interesa por esta publicación y por la mexicana el corno emplumado (1962-1969), con la que Grinberg sostiene profusos intercambios. La "Nota de la dirección" se hace eco de la "fraternidad difusa" (Gatto, 2012, p. 174) promovida por Eco contemporáneo, basada en una amplia red de intercambios - vehiculizados principalmente por la correspondencia y la traducción-, entre los que sobresalen aquellos establecidos entre escritores latinoamericanos y representantes de la contracultura estadounidense (p. 185). En consonancia con la aspiración a construir una "comunidad paralela" (AA.VV., p. 53) global, el mapa literario que delinea la editorial sobreimprime el espacio mundial sobre el continental. A la vez que invoca la unión de los escritores latinoamericanos -imaginario geopolítico que postula una solidaridad tercermundista y un patrimonio común disponible para su difusión (Gilman, 2012, p. 27) -, incluye dicho imaginario en un nivel más amplio, "el mundo". Esta proyección cosmopolita retoma la aspiración a forjar un colectivo de artistas desterritorializado, cuya labor a favor del cambio vital se desarrolle por "contagio" de entusiasmo, a partir de una "condición marginal" en relación a las instituciones culturales oficiales y las estructuras burocráticas de los partidos y grupos políticos (Gatto, 2010, s/p).

En una carta enviada el 8 de agosto de 1966 a el corno emplumado (publicada en la sección Cartas / Letters del No 21), el joven Gandolfo (1967) da cuenta del interés que le ha suscitado la lectura de sus números:

Hace unos días viajé a Buenos Aires y compré tres números de El Corno. Me gustó a muerte. Hace uno o dos años que comencé a escribir poesía y cualquier hecho que difunda o aglutine el esfuerzo delirante de la poesía actual por frenar el suicidio total de lo humano me parece extraordinario. Para colaborar aunque sea en mínima parte a esto, les envío algunos de mis poemas. Un gran abrazo (p. 126).

La adhesión y admiración ante "el esfuerzo delirante de la poesía actual por frenar el suicidio total de lo humano" deja su huella en la "Nota de dirección”, que define la actividad literaria como un "esfuerzo solidario y vital".

el lagrimal se impregna del neohumanismo de estas revistas, caracterizado por una "crítica iconoclasta frente a las sociedades tecnocráticas de la segunda posguerra" (Manzano, 2017, p. 118) y un rechazo a los "excesos del racionalismo" (p. 123). Al igual que estas, otorga centralidad a la poesía como "modo de intervención” (Gatto, 2010, s/p) en el proceso de emancipación social. Según la carta citada, la escritura poética contribuiría a "frenar" el proceso de alienación que amenaza con destruir "lo humano". Este posicionamiento se articula con la emergencia a escala continental de una nueva manera de afrontar los vínculos entre la praxis literaria y el conjunto de la sociedad. Claudia Gilman releva, en el seno de la tendencia antiintelectualista de izquierda, una "apuesta por el cultivo de nuevos formatos y géneros literarios, como el testimonio, la poesía y la canción de protesta”, que ofrecerían la posibilidad de extender "las condiciones de producción y recepción" (2012, p. 345). A medida en que los narradores del boom pierden "legitimidad ideológica" debido a su conexión con el mercado editorial, la poesía se convertiría en el discurso que mejor encarna el potencial "político-revolucionario" de la escritura (2012, p. 345). Este "pasaje", calificado tanto en Marcha como en Casa de las Américas como "boom de la poesía” (2012, p. 345), tendría lugar entre 1969 y 1971 . En este contexto, es necesario destacar que la centralidad otorgada a la escritura poética en $e l$ lagrimal (Gandolfo, 2015, p. 17) no implica la predilección de un género por sobre otros, sino la postulación 
de un modo de aproximarse a la praxis literaria, que hace de "la palabra" el motor y epicentro de los cambios históricos.

En estrecho diálogo con la iniciativa artística difundida por Eco contemporáneo y el corno emplumado, abocada a una "revolución interior" (AA.VV, p. 54) basada en un "incremento del área de conciencia" (55), el proyecto poético de el lagrimal sostiene como premisa el valor gnoseológico y perceptual de la experiencia literaria. En efecto, la impronta revolucionaria de la década sería percibida por los "mufados" y sus compañeros de ruta "en el sentido intrínseco del término: como un "cambio importante en el estado de las cosas", y no como un "cambio violento en las instituciones políticas, económicas o sociales de una nación” (Grinberg, 2010, p. 31). El impacto político de la escritura —que la actitud poética subraya al privilegiar la potencia creativa del lenguaje por sobre su instrumentalización en función de la comunicación de contenidos - respondería a la integración de formas originales de pensamiento y sensibilidad al conjunto de la sociedad. Este punto de vista es enfatizado por otros textos clave publicados en la revista.

El No 7 (mayo de 1970) se abre con una cita del poeta martiniqués Aimé Césaire, cuya ubicación liminar en el número le otorga el valor de un mensaje editorial:

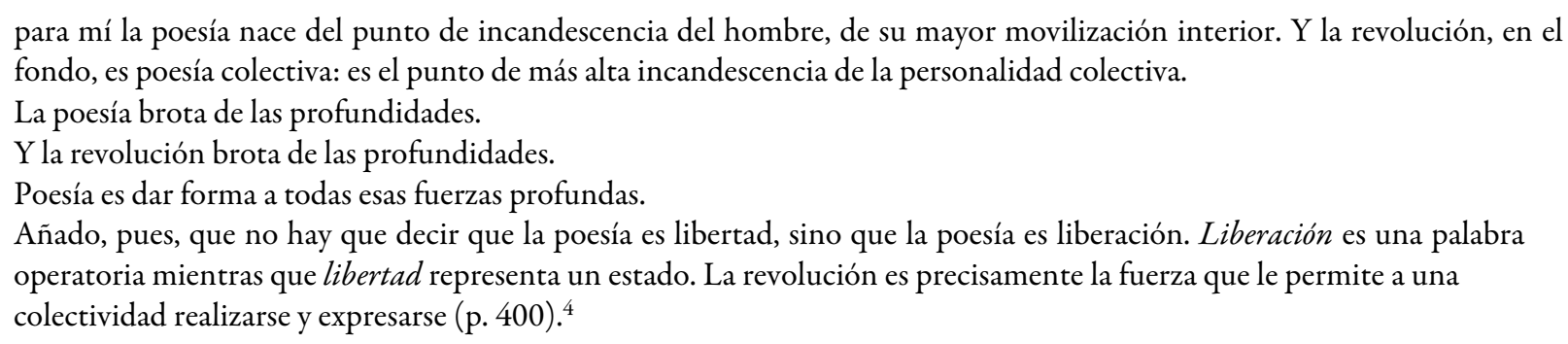

El pasaje, extraído de una entrevista realizada por la periodista Sonia Aratán durante el Congreso Cultural de La Habana de 1968, sostiene un paralelismo entre la "movilización interior" que encarna la creación poética y la insumisión que desencadena el proceso revolucionario. Ambas desembocarían en un punto de "incandescencia" en el que las "fuerzas profundas" consumarían su empuje. La poesía jugaría un rol fundamental en este proceso, ya que permitiría que la reverberación de los ímpetus de cambio alcance su manifestación expresiva. La "liberación" consistiría en la proyección o el brote de una turbulencia innominada hacia la superficie del lenguaje a través de una forma. El desarrollo máximo de las fuerzas transformadoras de una sociedad coincidiría con la gestación de una matriz significante que transmita y a la vez modifique los movimientos subterráneos del organismo social.

La entrevista es reproducida completa en la sección "Reportaje" que encabeza el No 8. La presentación sin firma que la antecede se detiene en el problema de la comunicación poética a partir de la revisión del vínculo entre el compromiso de Césaire con la lucha por la descolonización política e ideológica del "pueblo negro" ( $e l$ lagrimal, 2015, p. 471) y la densidad simbólica de su escritura: "Su obra creativa está indisolublemente unida a la labor política en favor de los negros de Martinica (...). Curiosamente, su lenguaje poético no condesciende a facilidades, sino que utiliza un complicado estilo donde predominan las metáforas y los simbolismos” (p. 471). Esta observación pone en juego dos acepciones de la función comunicativa: habría una escritura llana y asequible, que delataría una actitud condescendiente hacia los lectores, y otra que no renunciaría al volumen simbólico de la lengua. En una de sus intervenciones, Césaire se inclina por esta última: la transmisión de sentidos no explicitados respondería a "una dimensión poética que ignoramos" (p. 478). La comprensibilidad de un texto no dependería de su simpleza, sino de un "más allá de las palabras" que garantizaría el "acuerdo secreto y profundo" (p. 477) con el lector. El poeta sería el portavoz de una visión utópica, que mostraría - a través de una "recreación" (p. 473) - "plenamente realizado" aquello que aún se encuentra "en estado embrionario" (p. 475). La "búsqueda del hombre integral” (p. 476) que guía todo proyecto revolucionario comenzaría por una conquista imaginaria. La vanguardia política se fundiría con el frente poético en la cruzada de liberación de las fuerzas creativas del porvenir que alberga la "personalidad colectiva” (p. 472). 
El interés de los editores por la declaración de Césaire respecto al tópico revolucionario señala su adscripción tácita a una visión vitalista-inmanentista de la actividad poética, que reconoce una potencia transformadora en la "la interacción entre principios materiales y fuerzas" (Aréchiga, 2018, p. 167). Esta visión sostiene que la escritura no se limita a ser un medio de representación de lo existente. Contra el dominio especulativo sobre los objetos a los que esta se enfrenta, supone la inmersión del sujeto en la materia del lenguaje. El trabajo textual no se ceñiría a una operación intelectiva que dispone giros y formas en la superficie textual y forja de esa manera una imagen del presente; se desarrollaría, por el contrario, en el seno de la palabra, que pertenece a la totalidad dinámica de la vida (en la que la reciprocidad del todo y sus partes no daría origen a una unidad estática sino a una en constante devenir). La creación poética implicaría un quehacer material que transforma las condiciones bajo las cuales los hombres perciben y transitan su existencia individual y colectiva, a partir de la movilización de energías innominadas. En palabras de Paul Douglass, la escritura "vuelve inteligible el mundo dado al sumergirlo en su propio fuego creador" (1987, p. 256, trad. propia). La idea de una revolución y una poesía que brotan "de las profundidades" parte de la premisa de que existen fuerzas creativas desconocidas que actúan tanto en el interior de cada sociedad y del acto escriturario, desligadas de constantes o leyes inmutables que rijan su desenvolvimiento. En la inmanencia de una vida en común, las revueltas de la historia y del poema - condensaciones cambiantes del plasma vital que Césaire percibe como una "naturaleza polimorfa incesantemente creativa" (Jones, 2010, p. 176)— ocurren bajo la temporalidad incandescente de la contingencia.

El énfasis sobre la potencia del presente como una intensidad sustancialmente distinta a la lógica cronológica o evolutiva se enlaza con la actitud vitalista que encauza el lagrimal, próxima a la de poesía buenos aires (1950-1960). Ambos Gandolfo, D'Anna y Dizestablecen una amistad epistolar con dos de sus principales editores, Aguirre y Bayley, acompañada de visitas ocasionales a la capital. La admiración hacia esta revista (Gandolfo, 2015, p. 17) señala el interés de modernización literaria que acucia al grupo, que (sin buscar remedar su programa estético o rendir tributo al movimiento del que es exponente) recupera y reinventa su ímpetu renovador.

Para Freidemberg (1988), poesía buenos aires representa "un punto de inflexión y un núcleo de condensación en la poesía argentina", que marca su inserción definitiva "en la modernidad" (1988, p. 22). Si el lagrimal se manifiesta como uno de los herederos de este "mito" (1988, p. 22), lo hace a partir de un registro singular de lo nuevo. Mientras que la configuración de la temporalidad en la primera se encuentra atravesada por las fuerzas del “agobio” y del “júbilo" (Stedile Luna, 2019, p. 86), la publicación rosarina recrea esta ambivalencia a partir de la percepción de otro tipo de presente estancado - que no se agota en el de la suspensión de la historia-: el de la cultura local.

Gandolfo (1986) describe el ambiente cultural de Rosario a fines de los sesenta como una "pampa de cemento" (p. 18). Esta metáfora espacial remite a dos formas de experimentar el presente, cuya fricción define la modernidad situada de "los lagrimales": la monotonía a la que hace alusión la imagen del desierto pensada aquí como la ausencia o el retraso de novedades culturales - y la mutación permanente que conlleva el desarrollo social y comercial de la ciudad (referido a partir de su elemento por excelencia, el cemento). Ni plenamente provincianos ni metropolitanos, los integrantes se identifican con el deseo de modernización literaria, atravesado por la curiosidad voraz y la "sensibilidad cosmopolita" (Fernández Bravo, s/p) que distingue su condición provinciana. El mito de conquista de la modernidad poética por parte de poesía buenos aires deja su huella en la tarea "delirante" (Gandolfo, 1967, p. 126) a la que se lanza la revista. La disposición entusiasta constituye un ethos grupal (denominado por los editores el "espíritu del lagrimal” (Gandolfo, 1986, p. 18), que compromete un ímpetu de trabajo — basado en la convicción de que es posible sobreponerse con "esfuerzo" (Gandolfo, 1967, p. 126) a las dificultades materiales inherentes a todo emprendimiento cultural autogestivo- y un sentido del humor particular — una alegría próxima al desparpajo que se recorta contra la solemnidad comúnmente reconocida al oficio literario. 
La publicación de " 5 tesis sobre poesía" de Aguirre subraya la afinidad de el lagrimal con el vitalismo poético de poesía buenos aires, que concibe el poema como "el resultado y a la vez el desencadenante de un modo 'poético' de vivir” (Freidemberg, 1988, p. 22). Este texto de tenor ensayístico (cuyo título remeda las "noventa y cinco tesis sobre las Indulgencias" (p. 478) que expone Martín Lutero en Wittenberg en 1517) se basa en una conferencia dictada en la Biblioteca Argentina de Rosario en 1975, y es cedido por el autor a la revista a raíz del lazo de reciprocidad que sostiene con sus integrantes.

Las tesis expuestas se proponen "el examen de algunos presupuestos corrientes acerca de la poesía y los poetas" (el lagrimal, 2015, p. 478). Contra la abstracción de la poesía como una esencia autónoma no adscrita a ningún campo, la primera tesis de Aguirre afirma que esta "no existe en cuanto algo concreto que pueda ser definido por fuera de la literatura” (p. 478), es decir, de la escritura, caracterizada por la segunda sentencia como un "acto de creación" que "trasciende" las habilidades técnicas. La definición de los poetas como "hacedores de poemas" es descartada, ya que su énfasis en el conocimiento y el buen uso de los recursos retóricos no permitiría vislumbrar que la escritura se manifiesta como un "acontecimiento existencial" (p.479), ajeno a toda experticia. Para pensar los efectos desencadenados por esta vivencia, Aguirre apela en su tercera tesis a diversas formulaciones de lo inefable: las "reacciones emocionales", "revelaciones" o "deslumbramientos" que produce un texto traducirían "la sensación de haber sido 'tocados' por algo que tiene mucho de indecible" (p. 481). Los principios enumerados confluyen en la constatación de que las únicas unidades positivas del quehacer poético serían "los poemas", definidos como "constelaciones significantes de palabras que operan en el curso de nuestras vidas” (p. 482). Estas poseerían una existencia fáctica, desde el momento en que su acontecer compromete al hombre real. Cada poema sería una palabra que "ocurre, que nos ocurre, que nos coloca en determinada situación" (p. 481). La zona disciplinar sobre la que se proyecta todo acto creativo no sería, según la cuarta tesis, la estética o la retórica, sino la poética, cuyo dominio es el "campo" "vasto y misterioso" (p. 481) del lenguaje. Finalmente, toda escritura comprometería una ética, es decir, un “'ajuste’ del ser humano con su situación histórica” (p. 482). Esta tesis responde al imperativo epocal del "compromiso del poeta" (p. 483), que desembocaría en "la producción de determinados poemas que solo son desarrollos retóricos de temas de índole histórica o social” (p. 483). En contrapunto con la tematización de lo político, "El poema no habla de la realidad: la hace. Y, con ella, nos hace a nosotros, que, a su vez, también la hacemos" (p. 483). La ilusión referencial deja paso en la argumentación de Aguirre a una conciencia sobre la performatividad del acto creador, cuya irrupción traería aparejada la configuración de un cosmos irrepetible. La consistencia significante del poema volvería presente una realidad y una subjetividad específicas, cuyo poder convocante (su capacidad de "tocar" a los lectores) sería inseparable de un "misterio". Lo "indecible" que pone en escena la enunciación poética aparece como una resistencia a la nominación y la clausura del sentido, ya que no perseguiría la transmisión de un significado claro y asequible, sino la "condición integral de la existencia de la poesía en la vida" (Stedile Luna, 2019, p. 266). Ante el imperativo realista, Aguirre esgrime la presencia enigmática del poema, constelación verbal que actúa en la vida a partir de una forma de pensamiento insurgente frente a la razón del signo.

El vitalismo poético con que se identifica el lagrimal es puesto en escena por los textos publicados de Césaire y Aguirre. Ambos reconocen una motivación emotiva o anímica para el acto poético. La significación de este se asociaría a un más allá del juicio especulativo - ya se trate del fondo de la personalidad o de una región espiritual - cuya emergencia traería aparejado el descubrimiento de nuevas formas de existencia. El compromiso modernizador que asume el lagrimal persigue el hallazgo de obras originales que desplieguen nuevos modos de ver y sentir. La percepción no tiene aquí un sesgo impresionista, ya que se le confiere un valor cognoscitivo y performativo. La escritura no comunicaría significados a través de un uso instrumental del lenguaje, ya que estaría inmersa en su sustancia y encontraría en ella fuerzas vitales capaces de trastocar los órdenes y sentidos instituidos. Tal como subraya Battilana (2008), la "Nota de la dirección” asume que trabajar sobre el cuerpo de la palabra es actuar sobre un "elemento" perteneciente al orden de lo real (2008, p. 157). Este quehacer conlleva, por lo tanto, la transformación de una porción de mundo. 
Si la figura del poeta combatiente que predomina en el campo cultural latinoamericano de principios de los setenta sortea las mediaciones entre la esfera intelectual y la política en pos de la primacía del "hombre de acción" (de Diego, 2001, p. 47), el proyecto de el lagrimal interroga este tópico a partir del desplazamiento de la energía revolucionaria hacia el interior del proceso creativo. Sin rechazar las representaciones vigentes sobre el poetizar, el vitalismo poético que encarna la revista las pone en contacto con otras figuras de poeta, atravesadas por la tensión entre la percepción de un presente histórico marcado por la pulsión tecnocrática y un tiempo mítico o profético, en el que se pone en juego una dimensión espiritual refractaria a la razón utilitarista.

\section{Conclusión}

Las intervenciones críticas abordadas afirman que la escritura literaria no representa tan solo un oficio, ya que involucra una experiencia vital. La proximidad entre la praxis cotidiana y la actividad poética aquí delineada resulta irreductible al imperativo de compromiso político que asedia a los escritores entre mediados de los aos 50 y la primera mitad de los 70 (Terán, 1991). Tal como cuenta Elvio Gandolfo (2015), “los lagrimales" se sienten ajenos a los planteos de origen sartreano respecto al rol histórico de los escritores. En contraste con la coherencia propositiva de estos discursos epocales, la revista afirma tácitamente que la potencia transformadora de la actividad poética no puede ser subsumida a un programa estético o político.

El poder renovador y la función cognoscitiva que la "Nota de la dirección" de el lagrimal adjudica a "la palabra" señalan la asunción de un compromiso poético singular, cuyas coordenadas son delineadas en las intervenciones citadas de Césaire y Aguirre. Las argumentaciones de ambos autores funcionan como proyecciones discursivas de ciertos ejes problemáticos que vertebran el proyecto tácito de la publicación. En primer lugar, el vínculo entre la creación poética y el cambio social es abordado a partir de un desplazamiento del significante "revolución" hacia el plano inmanente del quehacer literario: la escritura poética conllevaría una "liberación" (Césaire, p. 472) interior. En segundo término, la comunicación con el lector no dependería ni de la intención representativa ni de la claridad estilística, sino de la "movilización" (p. 472) o el "deslumbramiento" (Aguirre, 1952, p. 481) que despiertan los poemas. La escritura pondría en marcha fuerzas vitales indeterminadas, cuya expresión desafía la lógica utilitarista sobre la que se erige el proceso de modernización contemporáneo. La irreductibilidad de la praxis poética a la experticia técnica daría cuenta de una incandescencia anímica o un "misterio" (Aguirre, 1952, p. 481) que sobrepujan el imperio del cálculo. La subversión simbólica del poema suspendería todo orden y sentido instituidos y crearía su propia historicidad radical.

\section{REFERENCIAS}

AA.VV. (2010 [1964]). Nueva Solidaridad. Declaración de México. En M. Grinberg (Ed.), Poesía y Libertad: manifiesto del Movimiento nueva solidaridad (pp. 53-56). Rosario: Fundación Ross.

Aguirre, R. G. (1952). Presencia de la realidad en la poesía. poesía buenos aires, 9, 1.

Aréchiga, V. (2018). El concepto de vida en El alma del mundo de Schelling. Metatheoria, 8(2), 157-168. Recuperado de https://ridaa.unq.edu.ar/handle/20.500.11807/2519?show=full.

Battilana, C. (2008). Critica y poética en las revistas de poesía argentinas (1979-1996) (Tesis doctoral), Universidad de Buenos Aires, Facultad de Filosofía y Letras. Recuperado de http://repositorio.filo.uba.ar/handle/filodigital/3 206? show $=$ full.

El lagrimal trifurca. Edición facsimilar. (2015). Buenos Aires: Biblioteca Nacional.

de Diego, J. L. (2001). ¿Quién de nosotros escribirá el Facundo? Intelectuales y escritores en Argentina (1970-1986). La Plata: Ediciones Al Margen. 
Del Gizzo, L. (2012). El fin de la elocuencia: figuraciones de lo poético y transformación lingüística en Buenos Aires a mediados del siglo XX. Cuadernos Americanos: Nueva Epoca 2 (140), 187-220. Recuperado de https://dialne t.unirioja.es/servlet/articulo?codigo $=3987936$.

Douglass, Paul. (1987). Such as the Life Is, Such Is the Form. Organicism Among the Moderns. En Burwick, Frederik (Ed), Approaches to organic form. Permutations in Science and Culture (pp. 253-273). Dordrecht: Boston studies in the philosophy of science.

Freidemberg, D. (1986). El poeta en la picota. Diario de poesía, 2, 22.

Freidemberg, D. (1988). 27 notas al pie de un mito. Diario de poesía, 11, 22-24.

Gandolfo, E. (1967). Fragmento de carta a el corno emplumado. el corno emplumado, 21, 126. Recuperado de http:// opendoor.northwestern.edu/archive/items/show/56.

Gandolfo, E. (1986). Conciencia, inconciencia y lluvia. Diario de poesía, 2, 18-19.

Gandolfo, E. (2015). De animales y revista. En el lagrimal trifurca. Edición facsimilar (pp. 17-27). Buenos Aires: Biblioteca Nacional.

Gatto, E. (2010). Viviendo en una red de subtes. La revista Eco Contemporáneo: creación y conexión, 1961-1969. Critica.cl. Recuperado de https://critica.cl/literatura/viviendo-en-una-red-de-subtes-la-revista-eco-contempora neo-creacion-y-conexion-1961-1969.

Gatto, E. (2012). El nuestro es un combate de creación: la revista Eco Contemporáneo, Argentina 1960-1969. Cali, 9, 169-198. https://doi.org/10.18046/recs.i9.1219.

Gilman, C. (2012). Entre la pluma y el fusil. Debates y dilemas del escritor revolucionario en América Latina. Buenos Aires: Siglo XXI.

Grinberg, M. (2010). Una generación indómita (Orígenes del Movimiento Nueva Solidaridad). En Poesía y Libertad: manifiesto del Movimiento nueva solidaridad (pp. 31-36). Rosario: Fundación Ross.

Jones, D. V. (2010). The Racial Discourses of Life Philosophy. Négritude, Vitalism, and Modernity. New York: Columbia University Press.

Manzano, V. (2017). Fraternalmente americanos: el Movimiento Nueva Solidaridad y la emergencia de una contracultura en la década de 1960. Iberoamericana, XVII(66), 115-138. https://doi.org/10.18441//ibam.17.2 017.66.115-138.

Sartre, J. P. (1969 [1948]). ¿Qué es la literatura?. Buenos Aires: Losada.

Silva Ibargüen, G. (2017). Texto, contexto e indices de el corno emplumado (1962-1969) (Tesis de posgrado), El colegio de San Luis. Recuperado de https://biblio.colsan.edu.mx/tesis/SilvaIbarguenGabriela.pdf.

Stedile Luna, V. (2019). Tempo y morales de la crítica: las revistas del surrealismo e invencionismo en Argentina entre 1948 y 1956 (Tesis de posgrado), Universidad Nacional de La Plata. Facultad de Humanidades y Ciencias de la Educación. Recuperado de http://www.memoria.fahce.unlp.edu.ar/tesis/te.1820/te.1820.pdf.

Wallerstein, I. (2006). Introducción. Aimé Césaire: colonialismo, comunismo y negritud. En A. Césaire, Discurso sobre el colonialismo (pp. 7-13). Madrid: Akal.

\section{Notas}

1 Dado que el nombre acotado con que suele reconocerse a la revista es el lagrimal, se recurre a esta denominación a lo largo del artículo. En adelante, todas las citas de la revista corresponden a su edición facsimilar (Biblioteca Nacional, 2015).

2 De aquí en adelante, las referencias correspondientes a la revista se realizan en base a la numeración de páginas de la edición facsimilar.

3 Tal como indica Gilman, la tarea de modernización cultural forma parte de la agenda de compromiso de gran parte de los escritores latinoamericanos del periodo (p. 147).

4 Césaire (1913-2008) es, junto con Leopold Senghor (1906-2001), uno de los principales escritores que reflexionan en torno al concepto de negritud en articulación con el de colonialismo. La cita señalada se corresponde con la poética del autor, que gira en torno a este problema y se apropia de "la búsqueda de una igualdad genuina, que no suponga la asimilación bajo algún supuesto modelo blanco o europeo y que permita la afirmación y la recuperación de la identidad de 
los que han sido históricamente oprimidos" (Wallerstein, p. 8). La reivindicación se basaría, según Donna V. Jones, en un misticismo vital que se nutre de la vertiente irracionalista de la filosofía europea de principios de siglo —especialmente de las obras de Friedrich Nietzsche y Henri Bergson-, y sostiene "la consanguinidad de todas las formas de vida, obliterada en la conciencia moderna a partir del método de clasificación capitalista, enfocado en las diferencias empíricas" (p. 10, trad. propia).

5 Aguirre sintetiza esta posición en "Presencia de la realidad en la poesía” (1952): "La poesía se aleja de la intelectualización del 'misterio prodigioso de la vida' en pos de un conocimiento afectivo, exaltado de la realidad” (p. 1). El tipo de saber apasionado que transmite la escritura poética se conectaría con la experiencia de una intensidad vital. Luciana del Gizzo (2012) explica que para la revista la palabra poética "no sólo actúa al interior del lenguaje, sino que plantea vínculos directos y por eso más genuinos con la vida; interviene lo real con el acto desnudo de poetizar” (p. 213). 